\section{Précis de microscopie}

Technique, expérimentation, diagnostic. Par M. Langeron. Septième édition entièrement refondue. Pp. viii +1430. (Paris : Masson et Cie., 1949.) 2600 franes.

T HE new edition of this well-known text-book fulfils expectation. The book has two main attributes that together make it preferable to most of its competitors: it has the coherence that results from its being written by a single author ; and there is more scientific explanation in it, and less purely empirical matter, than in most other books on microtechnique. The chemistry underlying staining reactions, etc., is explained in a simple, direct manner ; some of these explanations are particularly well done (for example, the account of the use of methylene blue and related dyes in staining blood-smears).

There is abundant evidence that the author has both theoretical knowledge and practical experience in very diverse parts of his subject. Much good common-sense is to be found in what he writes about microscopy itself, particularly in his strong recommendation of the opal bulb as an illuminant, and his insistence on the good results obtainable with condensers that are not highly corrected, in routine work ; but he does not sufficiently stress the importance of the field-stop, nor does he adequately explain the focusing of the bull's eye, when this is used with an intense light-source. Also, he uses a very much narrower illuminating-cone than most experienced microscopists. The section on photomicrography is weak : the treatment is not general enough, too much space being devoted to a particular apparatus. There are a few errors, as is perhaps inevitable in such a large work as this. Thus, the author says that in phase-contrast microscopy the objective is used at full aperture, which would only be true if the phaseplate annulus were situated at the periphery of the aperture of the objective. He also makes the astonishing statement that dark-ground illumination is invariably produced by total reflexion at the surface of the coverslip. These, however, are minor matters.

The book can be confidently recommended to British microscopists and micro-technicians.

JOHN R. BAkER

\section{Electrical Measurements and the Calculation of the Errors Involved}

By D. Karo. Part 1. Pp. 191. (London: Macdonald and Co. (Publishers), Ltd., 1950.) 18s. net.

MOST text-books on practical physics include a chapter dealing with the calculation of errors involved in experimental work, and one wishes that students would digest this at the earliest opportunity. Very often this wish is unfulfilled, and students, especially in the early stages, proceed with the experiments without a full appreciation of the degree of accuracy to be expected at the end.

In this book Mr. D. Karo compels the student to consider errors, both systematic and accidental, for he demonstrates the relative usefulness of different methods of measurement by calculating the errors involved in each and the limitations of various instruments, and also indicates the conditions in which each should be used. It is true the work covers the whole syllabus of the final degree examination in electrical measurements, but the book can be used with profit even by students preparing for the intermediate examination, for this latter is the time when they should begin to appreciate the value of their experimental observations; the first two chapters should certainly give such students invalu. able information.

The book starts admirably: "A measurement of any kind is of use only when the limits of the maximum possible error are known". If only students would realize this early it would save a lot of time and trouble. Altogether, this is an extremely useful book, particularly for finals students, research workers and engineers.

\section{Relations entre les phénomènes solaires et géo- physiques}

(Questions d'actualité éditées par les Annales d'Astrophysique et les Annales de Géophysique, 1 : Colloque International tenu à Lyon en 1947.) Pp. 312. (Paris : Éditions de la Revue d'optique théorique et instrumentale, 1949.) 1800 francs.

WHIS record of papers, prosented to the Conference on Solar-Terrestrial Relationships which was held at Lyons in 1947, shows to even the casual reader what a wide range of phenomena are affected, or even controlled, by solar radiation, electromagnetic or corpuscular. Study of the sun is now of importance to physicists, radio engineers, geomagneticians and meteorologists, as well as to astronomers. That the author index to the volume reads like an international scientific directory confirms the world-wide appeal of the subject.

It is perhaps scarcely fair to expect more than the thinnest unifying thread running through the whole work : it is no more than a series of research papers of uneven quality on related topics, each accompanied by a record of the discussion it aroused at the Conference. Regarded as an interim report on work in progress on a very live subject, however, this should be on the shelves of every geophysicist and astronomer. It is a pity that the quality of the paper is barely adequate even for the letterpress; the attempt to reproduce photographs in half-tone on this same low-grade paper fails miserably.

\section{Organic Chemistry}

A Textbook for Science and Medical Students. By Dr. Frederick Prescott and Dr. Dudley Ridge. Second edition. Pp. iv +724 . (London : University Tutorial Press, Ltd., 1950.) 14s. $6 d$.

7 HE scope of this book is intended to cover the 1 organic chemistry required for the general. degree examination and that needed by second-year medical students. The chapters dealing with carbohydrates, purines, proteins and fermentation are fuller than usual, in order to meet the needs of medical students. In the second edition a new chapter on isomerism and polymerism has been added, in view of the increasing importance of plastics. The book follows the usual plan, and special emphasis is given to details of preparation, these sections being sufficiently detailed for laboratory use.

The methods of preparation and properties of groups of substances and individual compounds are clearly and comprehensively set out, and the text is well suited to students beginning the subject, who should find the book intelligible and interesting. Examination questions at the ends of the chapters will be useful to students and teachers. Although the classical theories, including stereochemistry, are adequately treated, electronic theories are excluded as beyond the scope of the book. This is a clear and good treatment of elementary organic chemistry. 